\title{
O "estar lá" no contexto da globalização: Imagens da Amazônia através dos ativistas britânicos
}

\author{
Andréa Zhouri*
}

\section{Introdução}

No CLÁsSico HEART OF DARKNESS, Joseph Conrad, autor de origem polonesa, considerado um dos maiores escritores em língua inglesa (Clifford, 1994), relembra:

"Agora, quando eu era pequeno, eu tinha uma paixão por mapas. Eu passava horas olhando a América do Sul, a África ou a Austrália, e me perdia em todas as glórias da exploração. Naquela época, havia muitos 'espaços vaz̧ios na terra', e quando eu via um que parecia particularmente convidativo no mapa (mas todos pareciam assim) eu colocava meu dedo nele e dizia: Quando crescer eu irei lá. O Pólo Norte era um desses lugares, eu me lembro. Bem, eи não estive lá ainda, e não devo tentar agora. O glamour acabou." (Conrad, 1995, p. 21-2; tradução e grifos da autora).

O glamour relacionado ao estar lá - naqueles imaginados 'espaços vazios na terra' - pode ter acabado para a imaginação européia sobre o Pólo

* Professora-adjunta do Departamento de Sociologia e Antropologia da FAFICHUFMG. 
Norte. Contudo, ele ainda persiste como uma força motriz a impulsionar os modernos viajantes ocidentais para a Amazônia. Alguns procuram aventura e 'felicidade junto à natureza'. Outros são guiados pelas perspectivas de novas oportunidades econômicas. Os cientistas vêem nela a maior biodiversidade do planeta a ser investigada; os antropólogos são atraídos pela diversidade cultural, enquanto os ambientalistas valorizam a floresta como recurso natural vital e lar daqueles cujo modo de vida está sendo ameaçado pelo capitalismo transnacional.

Nas últimas quatro décadas, diferentes perspectivas e movimentos ambientalistas têm se constituído como forças culturais e políticas nas sociedades ocidentais. Indubitavelmente, a Floresta Amazônica é um dos principais temas - e símbolos - do ambientalismo global. Como um tipo de fetiche ocidental - uma floresta que entra no século XXI quase intacta - a Amazônia representa a possibilidade de se imaginar novas formas de relacionamento entre sociedade e natureza.

Neste artigo, discutirei o engajamento dos ativistas britânicos com a Amazônia a partir, sobretudo, de suas recordações acerca de suas primeiras experiências na floresta. Uma vez que o 'estar lá' confere especial autoridade aos atores políticos que embarcam numa campanha globalizada, resulta relevante explorar os aspectos que são recordados e aqueles que são esquecidos, ou silenciados, pelos ativistas ao narrarem suas impressões sobre a Amazônia. Além disso, é importante considerar como tais experiências podem ter influenciado o modo como se percebem, assim como a seu país, enquanto atores no mundo, moldando desta forma suas concepções e práticas discursivas ${ }^{1}$.

O universo das ONGs (Organizações Não-Governamentais) é constituído por uma variedade de posições e perspectivas, para além das mais óbvias classificações das organizações enquanto conservacionistas, ambientalistas, de direitos humanos, sociais ou mesmo agências de desenvolvimento. A partir das histórias de vida dos ativistas das principais ONGs globais - como Greenpeace, Amigos da Terra (FoE), Fundo Mundial para a Natureza (WWF), Oxfam, Christian Aid e Anistia Internacional - a pesquisa na qual este artigo se baseia traçou os elementos

Para uma discussão sobre memória e narrativas ver, dentre outros, Thompson \& Chamberlain, 1998. 
de suas trajetórias pessoais e sociais que influenciaram no engajamento com a Amazônia, produzindo, assim, uma forma particular de discurso e de relacionamento com a floresta.

O foco nas trajetórias pessoais e na história cultural e social dos ativistas deve-se ao fato de eles carregarem o ethos das ONGs. Eles são os agentes que implementam a agenda das organizações, e como tais, constituem-se como importantes atores no debate sobre a Amazônia. As marcas de seu habitus (Bourdieu, 1993), suas experiências sociais e culturais refletem-se na forma como constroem a Amazônia como tema, revelando as principais tendências que guiam as abordagens das diferentes ONGs. As entrevistas com os ativistas foram gravadas entre 1994 e 1997 para a pesquisa de doutorado Trees and People: an Anthropology of British Campaigners for the Amazon Rainforest. O quadro dos entrevistados foi composto majoritariamente pelos campaigners, ou seja, pelos ativistas profissionais especializados no tema da floresta amazônica, seja no quadro técnico das ONGs ambientalistas WWF, Greenpeace, FoE, ou nas entidades sociais como Christian Aid e Oxfam, seja nas organizações de direitos humanos e especificamente indígenas, respectivamente Anistia Internacional e Survival International.

Nesse sentido, três tendências entre os ativistas britânicos foram delineadas: árvores, gente e árvores \&o gente. Árvores abriga aqueles ativistas que enfatizam preocupações com a biodiversidade, gente engloba os que focalizam os temas da justiça social e do desenvolvimento, enquanto 'árvores \& gente' significa a síntese das duas tendências anteriores. As palavras árvores e gente são, aqui, utilizadas num sentido metafórico, como encapsulando, de um lado, preocupações com a conservação, preservação, proteção e usos sustentáveis do 'meio ambiente' e, de outro lado, simbolizando temas como justiça social, desenvolvimento e direitos humanos.

Um breve perfil dos ativistas, em cada tendência, poderá fornecer subsídios para a compreensão das diferentes narrativas apresentadas sobre a Amazônia. É interessante notar que os ativistas em árvores são geralmente encontrados nas principais organizações ambientalistas, tais como, WWF, Amigos da Terra e Greenpeace, independentemente das específicas orientações políticas e organizacionais de cada grupo (ver Zhouri, 2001b). Eles compõem uma geração mais jovem de ambientalistas, na casa dos 30 anos, que foram treinados nas áreas técnicas de 
ecologia, engenharia florestal, geografia, botânica e outras correlatas. Viajaram para áreas florestais na África ou na América Latina, sobretudo em função de suas atividades estudantis ou profissionais, ou seja, como 'trabalhos de campo'. Em geral, não apresentam uma vivência pessoal desses continentes ou mesmo conhecimento das línguas locais, por exemplo. Assim, os ativistas em árvores tendem a enfatizar suas qualificações profissionais e evitam falar sobre suas experiências e sentimentos pessoais, apresentando-se como essencialmente técnicos.

Os ativistas em árvores \& gente representam uma geração anterior - geralmente têm entre 40 e 50 anos - e apresentam uma qualificação técnica diversificada, porém voltada para o campo das Ciências Sociais. Encontram-se espalhados em organizações menores ou redes de organizações, como, respectivamente, as ONGs Reforest the Earth e Gaia Foundation, bem como a rede WRM - Movimento Mundial pelas Florestas Tropicais. Mais do que uma orientação técnica, o envolvimento com a Amazônia está, neste caso, relacionado a considerações de ordem ética e política desenvolvidas desde os anos 1970. Alguns passaram pela experiência de viver em um país do 'Terceiro Mundo', estabelecendo laços pessoais e profissionais com determinadas comunidades indígenas ou organizações locais.

Por fim, ativistas inscritos na tendência gente apresentam uma agenda política relativa à advocacia dos direitos humanos, justiça social e 'desenvolvimento social'. Grosso modo, seu perfil sugere algumas similaridades com os ativistas de árvores \& gente, particularmente no que tange à qualificação profissional e composição etária. Entretanto, trabalham para organizações como Oxfam, Christian Aid, Anistia Internacional e Survival International, voltadas mais para a defesa dos direitos sociais, humanos e étnicos. Apresentam ainda uma história particular de envolvimento político com a América Latina e o Brasil, podendo ser identificados como 'latino-americanistas' ou 'brasilianistas'.

\section{○estar lá}

Um elemento comum entre os entrevistados é que todos experimentaram viagens e deslocamentos como parte de seu engajamento político. É comum, hoje, a afirmação de que, devido às formas globais instantâneas 
de comunicação e transporte, as distâncias tornaram-se reduzidas. A compressão tempo-espaço e o contato com culturas diferentes agora forjam as experiências pessoais do mundo de uma forma global ${ }^{2}$. Assim, diz-se que remotas áreas tornaram-se mais próximas e interligadas, assim como 'o exótico' tornou-se familiar. Contudo, isto não significa dizer que a intensificação dos contatos implica numa melhor compreensão ou comunicação com o 'outro'. Apesar dos ativistas compartilharem os mesmos princípios básicos, eles apresentam diferentes motivações para viajar, diferentes percursos e variáveis interações com a alteridade, produzindo, assim, diferenciadas formas de engajamento político. Por via de conseqüência, apresentam diferentes experiências e 'imagens' da floresta amazônica, com significados correlatos, que são criados e reproduzidos no contexto das ONGs britânicas.

O 'estar lá, ter experiência prática ou direta, aparece como um dos componentes mais importantes em todos os depoimentos ${ }^{3}$. Apesar do 'estar lá' conferir autoridade a um ator político que embarca numa campanha globalizada, o contato direto com a Amazônia pode levar à formulação de diferentes práticas discursivas e variáveis experiências políticas. As diferenças e tensões entre as três tendências, no Reino Unido, podem ser percebidas numa análise das memórias dos ativistas sobre suas primeiras viagens à Amazônia, por exemplo, através do que é lembrado e do que é esquecido. Considerando que a memória é tanto pessoal como socialmente construída, ela acaba por permear as práticas políticas, sendo, portanto, relevante discutir as conseqüências políticas de lembrar paisagens físicas e esquecer o panorama social, como no caso em questão.

Para efeito de análise, e tendo em vista os limites deste artigo, focalizarei as memórias de viagem dos ativistas que se inscrevem nas duas principais tendências elaboradas de forma contrastiva: árvores e gente.

2 Para uma discussão sobre globalização e cultura ver as diferentes perspectivas em Featherstone, 1991; Friedman, 1994; Giddens, 1995; Robertson, 1992, dentre outros.

3 Para o tema do 'saber local', ver Geertz, 1983. 


\section{Lembrando gente}

Ao recordarem a primeira visita à Amazônia, os entrevistados refletiam também, comparativamente, sobre sua própria sociedade. Assim, temas como: aventura, romantismo, ausência de consciência política, racismo, ausência de vida comunitária, tristeza, amor pelos animais, dentre outros, eram criticamente analisados como atributos próprios da cultura britânica. Mais ainda, eram referidos retrospectivamente, ou seja, em termos de um passado histórico, enquanto o Brasil, e sobretudo a Amazônia, eram sempre pensados em projeção, ou seja, com significados prenhes de possibilidades futuras.

Aventura e romantismo, considerados elementos culturais britânicos, sobretudo atributos da 'inglesidade', eram tópicos recorrentes na tentativa de atribuição de significado para uma viagem à Amazônia, como, por exemplo, nos depoimentos seguintes de dois ativistas inscritos na tendência gente 4 .

"Eu fui lá porque a Amazônia é a viagem da vida para nós. Ela é o sonho máximo de um aventureiro, certo? As pessoas sentam e contam histórias excitantes, como: 'eu fui para a Amazônia' ou...antes da Amazônia era o Pólo Norte, sei lá. A Amazônia é o máximo. Não há outro lugar na terra, realmente." (Mulher na faixa dos 20 anos, Oxfam).

"Eu estava certamente ciente dela [a Amazônia] ser um lugar muito romântico quando eu finalmente a visitei. As expectativas devem ter incluído isso tudo, no sentido dela ser uma das maiores jornadas do mundo, por assim dizer. Como visitar as pirâmides, ou andar pelo caminho dos Incas ou qualquer coisa assim." (Homem na faixa dos 40 anos, Save the Children Fund).

Tais observações evocam claras ressonâncias com a imaginação do escritor Joseph Conrad acerca da exploração dos 'espaços vazios na

4 Por razões políticas, atendendo à solicitação dos próprios entrevistados, seus nomes não serão apresentados neste artigo. 
terra'. Contudo, quando solicitados a falar sobre suas primeiras impressões da Amazônia, os ativistas em gente apresentavam, basicamente, as lembranças de cidades e pessoas - a paisagem social - , como nos trechos a seguir:

"Quando eu estive lá, foram as cidades que me surpreenderam mais. Eu fui à Belém e pensando: isto é realmente grande!... Não foi realmente até a hora em que nós tomamos o ônibus de Manaus para a selva que eu compreendi o que era a floresta e como era realmente viver lá. Mas a coisa que me surpreendeu mais foram as árvores, eu acho. Porque eu esperava árvores, árvores, árvores e floresta. E foi um choque, realmente, que da estrada para todo lugar era fazenda e gado...isso bateu como uma aventura, sabe. Quando nós tomamos o ônibus... cheio de brasileiros, sabe, garimpeiro que está indo para o trabalho na sua mina, UAU! Lá estavam as coisas que a gente tinha ouvido a respeito. E ele estava nos contando sobre o garimpo, e como ele era forçado a fazer aquele serviço porque ele era pobre... Essa é outra imagem que as pessoas têm... As pessoas vêem o problema como branco e preto. Há o bom e o ruim. Se você é índio você é bom, se você é branco, você é mau... Eu não sou uma pessoa ligada à floresta. Eu realmente não gosto de florestas. Eu acho a floresta - é quente, é muito úmida, o clima era horrível, e eu não me sentia em controle, realmente... Perigosa, animais... Urhhh..." (Mulher, 20 anos, Oxfam).

Apesar de, primeiramente, enfocar o panorama social, é igualmente interessante ressaltar o significado que uma 'aventura na selva' possa ter para ativistas de diferentes orientações. Ao invés de evocar uma imagem mais comum, como atravessar rios num ambiente exótico e perigoso, o que vem à tona, no depoimento acima, é um sentido de aventura, como o contato pessoal e direto com os problemas sociais e os conflitos amazônicos estudados e trabalhados por eles no Reino Unido. Esse também é um aspecto enfatizado quando falam das dificuldades em abordar a dimensão social, nas campanhas sobre a Amazônia, para o público britânico: 
"Intelectualmente, eu fico muito chateado com as pessoas na Grã-Bretanha, ou pessoas no Norte, que querem romantizar a pobreza; que querem romantizar ambientes nos quais as pessoas não têm acesso aos serviços fundamentais como saúde e educação... E pessoas, por exemplo, seringueiros na Amazônia que podem ter uma jornada de uma semana para alcançar um posto de saúde. Que, nesse sentido, vivem vidas muito duras, e que são extremamente vulneráveis a doenças e enfermidades, coisas que podem matar e prejudicar as pessoas... porque os indios realmente querem postos de saúde apropriados, e eles os querem ao alcance deles, eles querem escolas apropriadas... e televisão, ou o que seja... e ninguém perguntou: você gostaria de viver em Xapuri... numa cidade? Absolutamente não. Nenhum deles quer viver numa cidade... Essas são algumas das coisas que me impressionam." (Homem na faixa dos 40 anos, Save the Children Fund)

"[É muito difícil] falar sobre cidades, grandes cidades para as pessoas aqui [no Reino Unido]. Há muitas cidades no coração da Amazônia que são totalmente favelas. Elas não são planejadas. Elas foram construídas como base de garimpo ou serraria. Elas são horríveis. Eu acabei de chegar de uma cidade chamada Redenção, no sul do Pará. É uma pequena cidade, bonitinha, pavimentada, com lojas, com muitas pessoas de Goiás: 'louras', certo, 'civilizadas', etc... Há um sentido de respeito e tranqüilidade lá. Mas esta cidade está acabada. Os garimpeiros foram embora, os madeireiros foram expulsos pela Polícia Federal e outras forças federais. A cidade não tem economia. É violenta, mas você não vê. É como uma cidade de cowboys na fronteira... É um contraste porque ela é uma cidade mais ou menos rica. Mas, lá, dentro desta cidade, há índios que não têm nada. Eles são totalmente dependentes do garimpeiro, do minerador... Mas falar de cidades para o público britânico não é possível. Não vale a pena até hoje." (Mulher, ex-campaigner da Anistia Internacional e da Oxfam, faixa dos 40 anos). 
Apesar de apelos à 'racionalidade intelectual', como na sentença 'intelectualmente, eu fico chateado...', nota-se o forte componente sensível na abordagem sobre os temas da exclusão social no contexto da Amazônia. Tal sensibilidade, ainda, sublinha as contínuas críticas sobre como as imagens e expectativas românticas do 'Norte' acabam por inibir preocupações quanto aos direitos sociais. Assim, os ativistas em gente acabam por evitar referências explícitas às conexões entre os problemas sociais, objeto de suas atuações, e os problemas ambientais que afligem a região. Buscam diferenciar-se, tanto das imagens do senso comum europeu, quanto das supostas críticas dos brasileiros aos ambientalistas estrangeiros preocupados exclusivamente com a biodiversidade. Portanto, as interseções entre meio ambiente e desigualdade social são apenas tangencialmente abordadas por esses ativistas.

\section{Lembrando árvores}

Em contraste com as memórias dos cenários social e urbano apresentados pelos ativistas em gente, as narrativas dos ativistas em árvores sublinham suas experiências do ambiente natural amazônico, em estrito senso. As lembranças de cidades e pessoas encontram-se ausentes ou surgem de forma secundária. É relevante mencionar ainda que suas recordações mais pessoais sobre a Amazônia são induzidas pela pesquisadora, ao invés de se apresentarem no contexto de suas próprias reflexões, como nas entrevistas com os ativistas da tendência gente. Como disse acima, os ativistas em árvores pertencem a uma geração mais jovem, com qualificação no campo da engenharia florestal, ecologia e áreas correlatas. Suas falas tendem a ser moduladas por um discurso técnico profissional, sendo fortemente evitadas as reflexões de ordem subjetiva. Parecem, assim, prevenir-se contra inferências sobre emocionalidade e romantismo, como se pode observar na fala dos ativistas do Greenpeace que fizeram suas primeiras visitas à Amazônia num barco, durante um tour da organização, em 1994:

"Infelizmente, por causa da natureza do barco, nós não tivemos a oportunidade de ir dentro da floresta. Mas porque nós fizemos muitas reuniões no barco com outras ONGs, e conversando com as pessoas sobre o que elas estavam 
fazendo, eu achei isso muito inspirador e encorajador... E, é claro, a Amazônia é simplesmente, totalmente linda [risos e pausa].

\section{Como você se sentiu lá?}

Não, eu estava totalmente tomada pela... Deixando Belém... antes de irmos para o rio principal, foi incrível [pausa]. A coisa mais incrível que eu me lembro da Amazônia foi... nós tínhamos que ir numa viagem com os infláveis, os pequenos barcos, para um dia de visita numa pequena comunidade de seringueiros, e quando nós voltamos muito tarde da noite, estava muito escuro quando retornamos. Havia uma lua descendo, um pequenino afluente... Nós estávamos simplesmente fechados por esta floresta e foi tão incrível, e a coisa mais fantástica era o super poderoso cheiro da floresta. É a coisa que eu mais me lembro. Realmente incrível.

\section{Que tipo de cheiro?}

Bem, tipo espesso, pesado, fragrância, sufocante, mas um cheiro lindo, realmente um cheiro forte, poderoso. Aquilo eu achei realmente incrível. E é uma das mais fortes imagens que eu tenho... Correndo nesse barco sob um tipo de arco, uma viagem bem próxima da floresta e esta incrível fragrância, um tipo de perfume. Muito espesso. Então, esta é uma das minhas mais fortes lembranças da Amazônia mesmo." (Mulher na faixa dos 30 anos, Greenpeace).

É interessante assinalar, por contraste aos ativistas em gente, que não há aqui qualquer auto-reflexão sobre romantismo e aventura. Contudo, ao falar da 'beleza' da floresta nota-se um constrangimento ou cuidado, como sugerido, na passagem acima, pelo riso seguido por pausa, quando o tema finalmente emerge. Outro aspecto relevante a observar é que as reuniões com as pessoas ou organizações locais eram basicamente realizadas dentro do barco do Greenpeace, ou seja, em seu 'território', por assim dizer, em contraste ao 'misturar-se' com as pessoas locais nas jornadas de ônibus, sugerido pelos depoimentos dos ativistas em gente. Um elemento de aventura pode ser também identificado através de uma referência indireta às ações geralmente levadas a cabo pelo Greenpeace - por exemplo, quando a ativista menciona o ato 
de cruzar o rio, em um pequeno barco inflável, tarde da noite. O componente de aventura pode ser observado ainda na fala de um outro ativista do Greenpeace, que relata sua jornada à Amazônia, incluindo outros elementos, tais como um 'extraordinário e arriscado' confronto com 'forças poderosas', outro aspecto típico do ethos de sua organização (ver Hansen, 1993):

\section{Como foi sua experiência na Amazônia?}

Minha experiência? Bem, é Brasil.

O que quer dizer isso?

É um pouco caótico e as autoridades estavam nos causando muitos problemas. A marinha estava nos seguindo. Eles simplesmente ficam preocupados quando alguém fala sobre a Amazônia. É muito maior do que eu pensava. Você realmente... para entender a escala da Amazônia... isso foi muito impressionante para mim. Grandes áreas. É uma grande área. E ver como as pessoas vivem, e ver como a Amazônia é importante para as pessoas e para o movimento de pessoas e bens. E realmente entender, quer dizer, o principal transporte... e colonização. Eu acho que o rio Amazonas e seus afluentes são realmente a chave. E então, só de ver essas coisas em primeira mão, eu acho que é realmente importante. O maior impacto para mim é que eu tenho uma noção melhor do significado do Brasil como uma economia e um lugar ecológica e socialmente importante.

\section{Por que?}

Porque é grande. (Homem, faixa dos 30 anos, Greenpeace).

É importante sublinhar, na passagem acima, a descoberta, propiciada pelo 'estar lá, da importância da Amazônia para as pessoas como se a Amazônia fosse primeiramente concebida como um espaço demograficamente vazio ${ }^{5}$. Conforme o depoimento dos ativistas em

5 Uma imagem forjada historicamente: Amazônia como vazio demográfico, fronteira da civilização, território a ser ocupado, dentre outras que influenciaram uma concepção geopolítica sobre a Amazônia, expressa na marcha para o oeste, nos programas de desenvolvimento da década de 70 e, mais recentemente, com os projetos Calha Norte e o Avança Brasil. Comparar ainda a imagem acima com a idéia de Conrad sobre os 'espaços vazios na terra'. 
gente, o elemento de aventura parece relacionar-se a situações envolvendo conflito e confronto. Porém, diferentemente do significado de conflito concebido por aqueles, os ativistas do Greenpeace atribuem a si próprios o papel de agentes ou sujeitos da confrontação - como indicado na situação de ser seguido pela marinha e pela polícia, num país percebido como sendo 'um pouco caótico' - , ao invés de testemunhas dos conflitos e da violência social estabelecidos por diferentes segmentos na região.

Os relatos ainda expressam outro contraste relevante entre as duas tendências, no que diz respeito às suas diferentes percepções e imagens da população da Amazônia. Enquanto os ativistas em gente expressam surpresa pelo dado demográfico, ou seja, pela extensão em que a região lhes parece altamente ocupada, incluindo as concentrações urbanas em suas memórias, a experiência dos ativistas em árvores parece reforçar a ênfase na percepção dos lugares considerados 'vazios' ou isolados, como é possível notar no seguinte trecho:

"Foi uma surpresa ver o quanto os bancos do Amazonas mudam. Eu imaginava que ia ser só um tipo de parede de selva o tempo todo que estávamos lá. Mas, não era. Toda manhã, ao acordarmos, as margens eram totalmente diferentes: elas eram pequenas num dia e selva fechada no próximo, e um tipo de planície no outro, e montanhas no próximo. Então, aquilo era realmente uma surpresa. Eu não imaginava que seria assim... era cheio de variedades... Então, também era incrível as pequeninas comunidades, e apenas uma... você via uma pequena cabana e nada mais num período de um dia talvez... e outra cabana.... só nas bordas sem nenhuma multidão que as protegesse. Eu apenas tentava entender aquele estilo de vida. Eu nunca tinha estado em lugar tão isolado antes, apesar de ter viajado muito. Eu achei aquilo incrível também.” (Mulher, faixa dos 30 anos, Greenpeace).

Além de confirmar a percepção de isolamento, o 'estar lá promove a descoberta da diversidade dos ecossistemas da Amazônia, ou pelo menos da variedade de seu relevo, algo que pode ser contrastado com a experiência que se tem das florestas mais uniformes do continente 
europeu. Contudo, diferentemente da tendência gente, há, neste grupo, um silenciamento sobre os aspectos possivelmente mais 'negativos' da floresta, tais como o calor, os insetos, e particularmente a pobreza das pessoas na Amazônia. Presumivelmente, essas impressões e sentimentos podem ter sido resguardados pelos limites da vivência no interior do barco itinerante do Greenpeace. O sentimento de isolamento provocado pela imagem das pequenas comunidades e suas pequenas cabanas à beira do rio pode ser interpretado, a partir do universo dos ativistas em gente, como sendo uma leitura 'emocional'e romântica, enfim, como 'uma romantização da pobreza', nos próprios termos daqueles. Uma diferença entre as duas tendências pode ser identificada através dos comentários dos ativistas em árvores sobre a pobreza da comunidade de seringueiros por eles visitada - uma dimensão introduzida pela pesquisadora, quando a entrevistada referia-se à vida dos seringueiros como sendo um modo de vida muito 'simples' e 'honesto':

"[Eles eram] pobres, mas de um jeito engraçado, numa escala diferente, realmente. Porque eles podem ser vistos como pobres, mas por outro lado, eles têm o tanto de floresta que eles querem, sabe. Eles têm água, eles têm comida e recursos. E eles têm tudo que eles precisam para viver. Não é como se eles tivessem pouca comida, ou água ou algo assim. Mas do ponto de vista natural, de natureza, eles têm tudo do que necessitam para viver. E eles parecem bem contentes e felizes, e é bom. É uma sensação boa aquele tipo de felicidade simples e respeito pela natureza, e viver na natureza sem sentir que você quer mais." (Mulher, faixa dos 30 anos, Greenpeace).

Essa visão pode ser confrontada com a imagem apresentada pelo depoimento do ativista em gente, quando afirma, sobre os mesmos seringueiros:

“... na Amazônia, que podem ter uma jornada de uma semana para alcançar um posto de saúde. Que, neste sentido, vivem uma vida muito dura, e que são extremamente vulneráveis a doenças e enfermidades, coisas que podem matar e prejudicar as pessoas." 
No entanto, como argumentado pelo entrevistado, isso não significa dizer que essas pessoas queiram viver em cidades, mas, sim, que elas desejam acesso razoável aos serviços de saúde e educação em suas comunidades. Parece que a idéia de 'vida comunitária', para os ativistas em gente não exclui o acesso ao bem-estar social tal como concebido pela experiência ocidental. Para os ativistas em árvores, por outro lado, o conceito de bem-estar e riqueza parece essencialmente relacionado à idéia de acesso aos recursos naturais. Essa diferença faz com que os ativistas em árvores percebam os discursos dos ativistas em gente como próximos do discurso 'desenvolvimentista', confundindo-os com seus defensores.

\section{Conclusão}

Ao discutir a forma como os diferentes ativistas britânicos falam sobre suas experiências pessoais na Amazônia, a análise buscou sublinhar os elementos que eram lembrados e os aspectos que eram esquecidos, por entrevistados agrupados em duas tendências opostas. Alguns depoentes lembravam florestas e esqueciam cidades, por exemplo, enquanto outros enfatizavam a pobreza acima da riqueza dos diferentes ecossistemas. Assim, a idéia não foi discutir quais imagens eram mais reais ou verdadeiras que outras, mas apresentar os efeitos de sentidos produzidos quando diferentes perspectivas interagem num campo discursivo ${ }^{6}$.

As imagens da Amazônia são modeladas pelas trajetórias pessoais e sociais dos ativistas, tais como geração e qualificações profissionais. Assim, ativistas em árvores são treinados nas áreas de ecologia, engenharia florestal, botânica, dentre outras, e tendem, portanto, a enfatizar os aspectos relacionados à biodiversidade da Amazônia, ou seja, a paisagem física; enquanto os ativistas em gente, treinados no campo das $\mathrm{Hu}$ manidades e com um interesse particular pela América Latina e o Brasil, focalizam as cidades amazônicas, quer dizer, a paisagem social urbana.

6 As noções de campo ambiental e ambientalismo como perspectiva cultural, que inspiram a presente interpretação, foram mais detidamente discutidas em Zhouri (2001a e 2002). 
Uma vez que as imagens são tanto social como pessoalmente construídas, elas se constituem como elementos importantes da atividade política. Os ativistas das diferentes tendências estão engajados num debate sobre a Amazônia e têm tido uma influência mútua no imbricamento de 'árvores e gente' - meio ambiente e justiça social portanto, compondo posições e apresentando alternativas práticas para os canais de decisão (decision makers) e os segmentos econômicos de todo o mundo, atuantes na Amazônia. Obviamente, algumas imagens da Amazônia tendem a tornar-se mais pronunciadas na arena política global, tais como a Amazônia enquanto reservatório de recursos naturais para a produção e, por oposição, a Amazônia como o último e maior ecossistema tropical da Terra. Em ambos os casos, as culturas e sociedades amazônicas correm o risco de se tornarem incrivelmente invisíveis, enquanto as tensões entre preservação e desenvolvimento tendem a ser reproduzidas.

Sentimentos e atitudes ambivalentes para com a Amazônia são expressão do modo como a floresta representa a perspectiva de um novo relacionamento entre sociedade e meio ambiente. A Amazônia é geralmente imaginada e projetada no tempo futuro, mais do que articulada às suas realidades presentes. Este aspecto é particularmente ressaltado quando a Amazônia é pensada pelos ativistas em comparação ao seu próprio país. A Grã-Bretanha é, geralmente, e com desesperança, remetida historicamente ao passado, sobretudo o passado colonial, na mesma medida em que a Amazônia é concebida como 'natureza', sobretudo pelos ativistas inscritos na tendência árvores. Conseqüentemente, os ativistas que centram suas campanhas no tema do desflorestamento causado pelo comércio madeireiro, por exemplo, tendem a enquadrar a Inglaterra na posição de sociedade consumidora de madeira, enquanto o Brasil é equivocadamente reduzido, tão somente, à posição de país produtor. Esta concepção subestima o consumo de madeira no mercado doméstico e pode, portanto, limitar os resultados efetivos das campanhas e iniciativas transnacionais para proteger a Amazônia do desenvolvimento predatório ${ }^{7}$. Ela é resultado de uma visão que

7 Para uma tentativa de corrigir tal distorção, ver a pesquisa sobre o fluxo madeireiro apresentada pelo Instituto Imazon e Amigos da Terra "Acertando o Alvo. Produção e consumo de madeira na Amazônia", 1999. Para uma discussão mais aprofundada sobre esta crítica, ver Zhouri (2001b). 
naturaliza 'ambientes' históricos, sociais, culturais e políticos. Como na imaginação de Joseph Conrad sobre o 'novo mundo', as presentes sociedades e culturas na Amazônia e no Brasil podem tornar-se simultaneamente assombreadas pela preocupação global com a biodiversidade, assim como o desejo ocidental por 'espaços vazios na terra'.

\section{Referências bibliográficas}

ARNOLD, D. The problem of Nature. Environmentalism, Culture and European Expansion, Oxford, Blackwell, 1996.

BOURDIEU, P. Outline of a Theory of Practice. Londres, Polity, 1993.

CLIFFORD, J. The Predicament of Culture: Twentieth-Century Ethnography, Literature, and Art. Harvard University Press, 1994.

CONRAD, J. Heart of Darkness. Penguin Books, 1995.

FEATHERSTONE, M. Global Culture: Nationalism, Globalism and Modernity. Londres, Sage, 1991.

FRIEDMAN, J. Cultural Identity and Global Process, Londres, Sage, 1994.

GEERTZ, C. Local Knowledge. Nova York, Basic Books, 1983.

GIDDENS, A. Beyond Left and Right, Londres, Polity Press, 1995.

HANSEN A. "Greenpeace and Press Coverage of Environmental Issues". In: HANSEN, A. (ed.). The Mass Media and Environmental Issues. Leicester, Leicester University Press, 1993.

ROBERTSON, R. Globalization, Social Theory and Global Culture, Londres, Sage, 1992.

THOMPSON, P. \& CHAMBERLAIN, M (eds.) Memories and Genres. Londres, Routledge, 1998.

ZHOURI, A "Árvores e Gente no Ativismo Transnacional. As dimensões social e ambiental na perspectiva dos 'campaigners' britânicos pela Floresta Amazônica". In: Revista de Antropologia. São Paulo: USP, 44(1), 2001 (a).

- "Transnational Campaigns for the Amazon: NGOS Strategies, Trade and Official Responses" In: Ambiente \& Sociedade. Nepam-Unicamp, N.6, 2001 (b).

- "Ambientalismo e Antropologia. Descentrando a categoria de movimentos sociais". In: Teoria \& Sociedade (8), UFMG, 2002. 
Resumo: A Floresta Amazônica constitui-se num dos mais importantes temas - e símbolo - do ambientalismo global contemporâneo. Como um tipo de fetiche ocidental - uma gigantesca floresta que entra no século 21 quase intacta - a Amazônia ascende ao imaginário social ocidental, sobretudo o ambientalista, representando os prospectos de um novo relacionamento entre sociedade e natureza. O artigo discute o engajamento dos ativistas britânicos com o tema da Amazônia, centrando-se nos relatos de suas primeiras experiências de viagem à floresta. Assim como nas tradições antropológicas, o "estar lá" parece conferir autoridade especial aos atores políticos que embarcam numa campanha globalizada. Nesse sentido, torna-se relevante explorar os aspectos que são "lembrados" e aqueles que são "esquecidos" ou silenciados por ativistas de diferentes tendências culturais, políticas e organizacionais, ao recordarem suas experiências pessoais na Amazônia. Mais ainda, a análise considera de que forma tais experiências acabam por forjar uma consciência de estar no mundo, as percepções comparativas sobre seu próprio país, além de suas práticas políticas discursivas sobre a floresta. Afinal, quais as conseqüências políticas do ato de recordar árvores e esquecer cidades, e vice-versa, para o contexto da Amazônia?

PalaVras-ChaVe: ambientalismo; Amazônia; britânicos; memória.

'Being There' in the Context of Globalization: Images of the Amazon and BRITISHNESS

Abstract: The Amazon Rainforest is one of the most important topics - and symbol - of contemporary global environmentalism. As a type of Western fetiche - a huge forest that enters the $21^{\text {st }}$ century nearly intact - the Amazon arises to the Western social imagination bringing new prospects for the relationship between society and nature. The article presents a discussion of British campaigners' engagement with the Amazon, focusing on their recollections of their first hand experiences in the forest. As in Anthropological traditions, 'being there' seems to lend special authority to political actors embarking on a globalized campaign. Hence, it is relevant to explore what is 'remembered' and what is 'forgotten' by campaigners from different cultural, political and organizational backgrounds, as far as the memories of their first visit to the Amazon are concerned. Moreover, the analysis considers how such experiences end up by shaping their consciousness of being in the world, the perceptions about their own country and the discursive political practices towards the forest. After all, what may be the political consequences of remembering trees and forgeting people, and vice-versa, for the Amazon?

KEYwords: environmentalism; Amazon; britishness; memory. 